УДК 539.186.3, 544.22

\title{
Towards a Universal Embedded Atom Method Interatomic Potential for Pure Metals
}

\author{
Viktor E. Zalizniak* \\ Institute of Mathematics and Computer Science \\ Siberian Federal University \\ Svobodny, 79, Krasnoyarsk, 660041 \\ Russia \\ Oleg A. Zolotov ${ }^{\dagger}$ \\ Institute of Humanities \\ Siberian Federal University \\ Svobodny, 82, Krasnoyarsk, 660041
}

Russia

Received 15.01.2015, received in revised form 20.02.2015, accepted 25.03.2015

A new interatomic potential for metals based on the embedded atom method is proposed in this paper. Some approximation of electron density distribution is suggested from the basic principles of quantum mechanics. The functional form of the electron density distribution includes two adjustable parameters. The form of this distribution defines the pair potential and, in part, the form of embedding energy function. The parameters are determined empirically by fitting to the equilibrium lattice constant, cohesion energy, vacancy formation energy, low index surface energy and elastic constants. Potential parameters for $2^{7} 7$ metals (10 fcc metals, 9 bcc metals and 8 hcp metals) are presented. Potential is expressed by simple functions and can be used in molecular dynamics simulations of large atomic systems.

PACS: 34.20.Cf, 61.50.Ah

Keywords: interatomic potential, embedded atom method.

\section{Notation}

$a, c$ - equilibrium lattice constants,

$E_{c}, E_{v f}$ - experimental cohesive energy per atom and unrelaxed vacancy formation energy, $c_{11}, c_{12}, c_{13}, c_{33}, c_{44}$ - experimental crystal elastic constants, $B$ - experimental bulk modulus, $E_{c}^{(a)}, E_{v f}^{(a)}$ - calculated cohesion energy per atom and unrelaxed vacancy formation energy, $c_{11}^{(a)}, c_{12}^{(a)}, c_{13}^{(a)}, c_{33}^{(a)}, c_{44}^{(a)}$ - calculated crystal elastic constants, $B^{(a)}$ - calculated bulk modulus,

$Q$ - nucleus charge.

\section{Introduction}

In spite of considerably increased computer speeds, the application of ab initio methods for an atomistic simulation of materials is still limited to relatively small systems of atoms and relatively short simulation times. By contrast, the use of empirical interatomic potentials makes

\footnotetext{
*vzalizniak@sfu-kras.ru

†ozolot_@mail.ru

(C) Siberian Federal University. All rights reserved
} 
it possible to simulate much larger systems for much longer times. For this reason there is a demand for realistic interatomic potentials.

In this paper we propose a consistent and practicable interatomic potential for pure metals. In this section of the paper we introduce our approach to the development of interatomic potential. Section 1 describes a strategy of parametrization of interatomic potential. In section 2 we present the results of fitting and testing the potential for 27 metals. In section 3 we summarize our results and make some conclusions.

The potential developed in this work is based on the formalism of the embedded-atom method $(\mathrm{EAM})[1,2]$. In the framework of EAM, the total energy of a system can be written as

$$
E_{t o t}=\sum_{n=1}^{N} E_{n}, E_{n}=F\left(\rho_{n}\right)+\frac{1}{2} \sum_{\substack{m=1 \\ m \neq n}}^{N} \varphi\left(r_{n m}\right), \rho_{n}=\sum_{\substack{m=1 \\ m \neq n}}^{N} \rho\left(r_{n m}\right)
$$

here $E_{t o t}$ is total energy of the system of $N$ atoms, $E_{n}$ is the internal energy associated with atom $n, \rho_{n}$ is the electron density at atom $n$ due to all other atoms, $\rho\left(r_{n m}\right.$ is the contribution to the electron density at atom $n$ due to atom $m$ at the distance $r_{n m}$ from atom $n, F\left(\rho_{n}\right)$ is the embedding energy of the atom into the electron density $\rho_{n}, \varphi\left(r_{n m}\right)$ is the two body central potential between atoms $n$ and $m$ separated by $r_{n m}$. Interpretation and functional form of $\varphi(r)$, $\rho(r)$, and $F(\rho)$ depend on a particular method. The popularity of the EAM model results from its quantum mechanical justification, as well as its mathematic simplicity, which makes this model conducive to large-scale computer modeling.

In recent years, a number of EAM potential models for fcc metals have been proposed. For example, Sheng et al. [3] have developed EAM potentials for fourteen fcc metals. The potentials were developed by fitting the potential-energy surface of each element derived from high-precision first-principles calculations. The three determining functions were expressed with quintic spline functions for each element. Typically 15 equidistant spline knots were used for both the density and the pair functions, and 6 spline knots were used for the embedding function. This results in a great quantity of fitting parameters. Hijazi and Park [4] have proposed potential for seven fcc metals: Ag, Al, Au, Cu, Ni, Pd and Pt. This potential has six adjustable parameters. Dai et al. [5] have proposed an extended Finnis-Sinclair potential for six fcc metals: Ag, Au, Cu, Ni, $\mathrm{Pd}$ and Pt.

A potential for a bcc metal should predict an energetic stability of a more open (not close packed) bcc structure. Dai et al. [5] have developed an extended Finnis-Sinclair potential for six bcc metals: Fe, V, Mo, Nb, Ta and W. Lee et al. [6] have applied the second nearestneighbor modified embedded atom method (MEAM) to bcc transition metals, Fe, Cr, Mo, W, $\mathrm{V}, \mathrm{Nb}$, and Ta. In MEAM model the electron densities are defined as the sum of term with $\mathrm{s}, \mathrm{p}, \mathrm{d}$, and $\mathrm{f}$ symmetry from the neighboring atoms. By including these angular terms in the background electron density, angular forces are introduced into the model. MEAM potentials are up to 10 times less computationally efficient as compared to EAM potentials [7]. This is because the electron density in MEAM has more complicated expression involving sums over three-body contributions that depend on the angle $\theta_{i j k}$ subtended by atoms $j$ and $k$ at a central atom $i$. Wilson and Riffe [8] have presented an EAM model that accurately describes vibrational dynamics in the alkali metals $\mathrm{Li}, \mathrm{Na}, \mathrm{K}, \mathrm{Rb}$, and Cs.

Compared to both fcc and bcc metals, the hexagonal close-packed (hcp) metals have been studied relatively little, both experimentally and with simulations. The application of EAM to hcp metals is more difficult in comparison with the cubic metals. In fitting potentials for an hcp metal one should take care to ensure the required $c / a$ ratio which experimentally seldom equals exactly $(8 / 3)^{1 / 2}$ (it is the "ideal" value calculated for close packing of hard spheres). In addition there are 5 elastic constants, rather than 3 as in cubic metals. Pasianot and Savino [9] have made EAM-like potentials for hcp metals Hf, Ti, Mg and Co. They also showed that an 
EAM-like model cannot reproduce all elastic constants correctly for those hcp metals which have

$$
c_{13}-c_{44}>0 \quad \text { or } \quad \frac{1}{2}\left(3 c_{12}-c_{11}\right)<c_{13}-c_{44} \text {. }
$$

Such metals are e.g. Be, Y, Zr, Cd and Zn. Cleri and Rosato [10] have derived parameters of tight-binding potential for the hcp metals $\mathrm{Ti}, \mathrm{Zr}, \mathrm{Co}, \mathrm{Cd}, \mathrm{Zn}$ and $\mathrm{Mg}$. Comparison with the experimental data shows that they obtained a reasonable agreement for $\mathrm{Mg}$ and Co whereas the agreement is not satisfactory for other metals. Chen et al. [11] have proposed an EAM potential for five metals, $\mathrm{Co}, \mathrm{Ti}, \mathrm{Hf}, \mathrm{Zr}$ and $\mathrm{Ru}$. In order to simulate anisotropic properties of hcp metals two sets of parameters in the potential model was used. The equilibrium hcp structure contains only two types of planes with an alternating ABAB... arrangement. The first set of parameters determines the interactions between atoms in A-plane or in B-plane. The second set determines the interaction between atoms of A-plane and B-plane. Thus, this potential can be applied only to the problems where atomic structure is close to the equilibrium hcp structure. Baskes and Johnson [12] have developed a MEAM potential for hcp metals.

The purpose of this paper is to present consistent and practicable EAM model which can be applied to many widely used metals. Some approximation of electron density distribution is suggested in this paper. The form of this distribution defines the pair interaction and, in part, the form of embedding energy function. Such approach is physically justified because interaction in metals is governed by the electron density distribution of atoms.

\section{Potential construction}

Consider an atom with $N$ electrons. In the non-relativistic case many-electron wave function $\Psi$ satisfies the Schredinger equation [13]:

$$
-\frac{h^{2}}{8 \pi^{2} m_{e}} \Delta \Psi+U\left(\mathbf{r}_{1}, \ldots, \mathbf{r}_{N}\right) \Psi=E \Psi
$$

where $h$ is Planck's constant and $m_{e}$ is the electron mass. The Laplace operator $\Delta$ acts in the $N$-dimensional coordinate space. Potential energy is

$$
U\left(\mathbf{r}_{1}, \ldots, \mathbf{r}_{N}\right)=\sum_{\substack{n=1 \\ m=1 \\ m \neq n}}^{N} U_{0}\left(\left|\mathbf{r}_{n}\right|\right)+\frac{1}{2} \sum^{N} U_{1}\left(\left|\mathbf{r}_{n}-\mathbf{r}_{m}\right|\right)
$$

where $U_{0}$ is the potential energy of electron-nucleus interaction and $U_{1}$ is the potential energy of electron- electron interaction. To consider electrostatic interaction between atoms one can use the quasiclassical approximation where electron charge is "smoothed" around nucleus and the electron density is introduced. The density of an electron cloud is defined as follows

$$
\rho(\mathbf{r})=Q\left\langle\int \Psi^{2}\left(\mathbf{r}_{1}, \ldots, \mathbf{r}_{i-1}, \mathbf{r}, \mathbf{r}_{i+1}, \ldots, \mathbf{r}_{N}\right) d V_{1} . . d V_{i-1} d V_{i+1} . . d V_{N}\right\rangle,
$$

where angle brackets mean averaging over all possible permutations with respect to $\mathrm{r}$ and $\mathrm{r}_{i}$ and integration is performed over $3(N-1)$ coordinates. Suppose that $\psi_{k}(r), k=1,2, \ldots$ is a complete set of orthonormalised single- electron wave functions. Then any many-electron wave function can be expressed as a linear combination of products of single-electron wave functions as follows

$$
\Psi\left(\mathbf{r}_{1}, \ldots, \mathbf{r}_{N}\right)=\sum_{i} a_{i} \prod_{j=1}^{N} \sum_{k} b_{i j k} \psi_{k}\left(\mathbf{r}_{j}\right), \quad \int\left(\sum_{k} b_{i j k} \psi_{k}\left(\mathbf{r}_{j}\right)\right)^{2} d V_{j}=1,
$$


where index $i$ enumerates all possible many-electron states in terms of appropriate statistics and index $k$ enumerates all possible single-electron states. Then we obtain the following expression for the electron density

$$
\rho(\mathbf{r})=Q \sum_{i} a_{i}^{2} \psi_{i}^{2}(\mathbf{r})
$$

Consider a hydrogen-like atom. The normalized wave function in this case has the form in spherical coordinates [13]

$$
\psi_{n l m}(r, \theta, \varphi)=D_{n l}(r) Y_{l m}(\theta, \varphi) e^{-\gamma_{n} r},
$$

where $n, l, m$ are the quantum numbers, $\left.Y_{l m}(\theta), \varphi\right)$ are spherical harmonics and $D_{n l}(r)$ are some polynomials. After substituting wave functions (3) into (2) and averaging over the angles, we obtain

$$
\rho(r)=Q \sum_{i} a_{i}^{2} P_{i}^{2}(r) e^{-\alpha_{i} r}
$$

Here we express the sum of squares of polynomials $D_{n l}(r)$ with positive coefficients as the square of some polynomial $P_{i}(r)$.

We will calculate the interaction between the two atoms when the distance between them is relatively large so that only the outer electron clouds overlap. This corresponds to small values of $\alpha_{i}$. We will determine parameters of electron density distribution from experimental data so that the degree of polynomial $P_{i}$ should not be too high. As a first approximation, one can suggest the following form of the electron density distribution

$$
\rho(r)=\rho_{0}(1+\beta r)^{2} e^{-\alpha r}, \quad \rho_{0}=\frac{Q \alpha^{5}}{8 \pi\left(6 \alpha \beta+12 \beta^{2}+\alpha^{2}\right)} .
$$

The electric potential created by this electron density can be shown to be

$$
\Phi(r)=\frac{Q}{8 \pi \varepsilon_{0}}\left(\frac{2}{r}-\left(\frac{\alpha \beta^{2}\left(r^{2} \alpha^{2}+2 r \alpha+2\right)}{\left(6 \alpha \beta+12 \beta^{2}+\alpha^{2}\right)}-\frac{2 \alpha \beta(\alpha+2 \beta)(r \alpha+1)}{\left(6 \alpha \beta+12 \beta^{2}+\alpha^{2}\right)}+\alpha+\frac{2}{r}\right) e^{-\alpha r}\right),
$$

where $\epsilon_{0}$ is the vacuum permittivity. Consider the energy of electrostatic interaction between two atoms. The energy consists of three parts:

$$
U(r)=U_{n n}(r)+U_{s s}(r)+U_{n s}(r),
$$

where $U_{n n}$ is the energy of electrostatic interaction between nuclei, $U_{s s}$ is the energy of interaction between electron shells and $U_{n s}$ is the energy of interaction between nucleus and electron shell of other atom. They are

$$
\begin{gathered}
U_{n n}(r)=\frac{Q_{1} Q_{2}}{4 \pi \varepsilon_{0} r} \quad, \quad U_{n s}(r)=Q_{1} \Phi_{2}(r)+Q_{2} \Phi_{1}(r), \\
U_{s s}(r)=2 \pi \int_{0}^{\infty}\left(\int_{0}^{\pi}\left(\Phi_{1}\left(r^{\prime}\right) \rho_{2}\left(\sqrt{r^{2}+\left(r^{\prime}\right)^{2}-2 r\left(r^{\prime}\right) \cos (\theta)}\right)\right) \sin (\theta) d \theta\right)\left(r^{\prime}\right)^{2} d r^{\prime}+ \\
+2 \pi \int_{0}^{\infty}\left(\int_{0}^{\pi}\left(\Phi_{2}\left(r^{\prime}\right) \rho_{1}\left(\sqrt{r^{2}+\left(r^{\prime}\right)^{2}-2 r\left(r^{\prime}\right) \cos (\theta)}\right)\right) \sin (\theta) d \theta\right)\left(r^{\prime}\right)^{2} d r^{\prime},
\end{gathered}
$$

where $r$ is the distance between the centres of electron shells where nuclei with charges $Q_{1}$ и $Q_{2}$ are located. One can obtain the analytical expression for $U_{s s}$. However the expression is very cumbersome even in the case of two identical atoms and it is not presented here. A quantum 
mechanical effect of the exchange interaction plays an important role when electron shells overlap. To take into account this effect we introduce the adjustable parameter $\gamma$ and then write the two body central potential in the form

$$
\varphi(r)=\gamma\left(U_{n n}(r)+U_{s s}(r)+U_{n s}(r)\right)
$$

Substituting the analytical expression for $U_{s s}$ into (4) and rearranging the obtained relation gives the following form of the two body potential for identical atoms

$$
\varphi(r)=\varepsilon \cdot \exp (-\alpha r) \sum_{n=-1}^{6} a_{n}(\alpha r)^{n}, \quad \varepsilon=\frac{\gamma \alpha Q^{2}}{4 \pi \varepsilon_{0}}
$$

where parameters $a_{n}$ depend on $\alpha$ and $\beta$ :

$$
\begin{gathered}
a_{-1}=1, \\
a_{n}(\alpha, \beta)=\frac{p_{n+1}(\alpha, \beta)}{p_{0}(\alpha, \beta)}, \quad n=0, \ldots, 6 .
\end{gathered}
$$

Functions $p_{n}$ are of the form

$$
\begin{aligned}
& p_{0}(\alpha, \beta)=\left(\alpha^{2}+6 \alpha \beta+12 \beta^{2}\right)^{2}, \\
& p_{1}(\alpha, \beta)=0.3125 \alpha^{4}+5.125 \alpha^{3} \beta+31.5 \alpha^{2} \beta^{2}+88.875 \alpha \beta^{3}+98.1562 \beta^{4}, \\
& p_{2}(\alpha, \beta)=-0.1875 \alpha^{4}-0.875 \alpha^{3} \beta+1.5 \alpha^{2} \beta^{2}+16.845 \alpha \beta^{3}+72 \beta^{4}, \\
& p_{3}(\alpha, \beta)=-0.02 \alpha^{4}-0.5 \alpha^{3} \beta-2.44 \alpha^{2} \beta^{2}-3.875 \alpha \beta^{3}+2.125 \beta^{4}, \\
& p_{4}(\alpha, \beta)=-0.04 \alpha^{3} \beta-0.4375 \alpha^{2} \beta^{2}-1.5 \alpha \beta^{3}-1.875 \beta^{4}, \\
& p_{5}(\alpha, \beta)=-0.15 \alpha \beta^{3}-0.029 \alpha^{2} \beta^{2}-0.225 \beta^{4}, \\
& p_{6}(\alpha, \beta)=-0.008 \alpha \beta^{3}-0.01875 \beta^{4}, \\
& p_{7}(\alpha, \beta)=-0.00089 \beta^{4} .
\end{aligned}
$$

The first-principles calculations give the following important information about the general behavior of the embedding energy function [14]:

$$
\begin{aligned}
F(0) & =0, \\
F(\rho) & <0, \\
\frac{\partial F}{\partial \rho}(\rho) & <0, \\
\frac{\partial^{2} F}{\partial \rho^{2}}(\rho) & >0,
\end{aligned}
$$

where $\rho$ is the background electron density found in metals. The embedding energy function $F(\rho)$ is assumed to be in the following form:

$$
\begin{gathered}
F(\rho)=c_{0}+c_{1} \rho^{*}+c_{2}\left(\rho^{*}\right)^{2}+ \begin{cases}c_{3}\left(\rho^{*}\right)^{3}+c_{4}\left(\rho^{*}\right)^{4}+c_{5}\left(\rho^{*}\right)^{5}, & \rho \leqslant \rho_{e} \\
c_{6}\left(\rho^{*}\right)^{3}+c_{7}\left(\rho^{*}\right)^{4}+c_{8}\left(\rho^{*}\right)^{5}, & \rho>\rho_{e},\end{cases} \\
\rho^{*}=\frac{\rho}{\rho_{e}}-1,
\end{gathered}
$$

where $\rho_{e}$ is the equilibrium electron density and $c_{n}$ are some coefficients.

In practical applications of EAM potentials, it is also desirable to employ a switching function in order to terminate the potential and forces smoothly at the cut off distance because the 
energy conservation is sensitive to the truncation of the force field. For this purpose, a simple polynomial switching function $f_{c}(r)$ can be applied to the electron density distribution and to the pair potential in a region just below the cut off distance $r_{c}$ :

$$
\begin{gathered}
\varphi(r) \rightarrow \varphi(r) f_{c}(r) \quad, \quad \rho(r) \rightarrow \rho(r) f_{c}(r), \\
f_{c}(r)=\left\{\begin{array}{l}
1, \quad r<r_{s w} \\
d_{1}\left(r^{*}\right)^{3}+d_{2}\left(r^{*}\right)^{4}+d_{3}\left(r^{*}\right)^{5}, \quad r_{s w} \leqslant r \leqslant r_{c} \\
0, \quad r>r_{c}
\end{array} r^{*}=\frac{r}{r_{\mathrm{c}}}-1,\right.
\end{gathered}
$$

where $r_{s w}$ is the distance at which the switching function is applied. The values of coefficients $d_{1}, d_{2}, d_{3}$ follows from the conditions

$$
f_{c}\left(r_{s w}\right)=1, \quad \frac{d f_{c}}{d r}\left(r_{s w}\right)=0, \quad \frac{d^{2} f_{c}}{d r^{2}}\left(r_{s w}\right)=0 .
$$

\section{Parameterization procedure}

In order to define the potential of interaction between identical metal atoms one need to fit two parameters of the electron density distribution $\alpha$ and $\beta$, and coefficients of the embedding energy function (9). Consider a perfect, homonuclear crystal at zero temperature. Because all atoms are equivalent, we can associate the origin of the coordinates with some atom and rewrite (1) as

$$
E_{n}=F\left(\rho_{e}\right)+\frac{1}{2} \sum_{m} \varphi\left(r_{m}\right), \quad \rho_{e}=\sum_{m} \rho\left(r_{m}\right),
$$

where $r_{m}$ are the distances between neighbors and the sum is over neighbors. The distances are determined by the lattice parameters. The ground-state properties of solid metal can be calculated from (10). The lattice equilibrium is defined by the condition

$$
\frac{1}{2} \sum_{m} r_{m} \frac{d \varphi}{d r}\left(r_{m}\right)+\frac{\partial F}{\partial \rho}\left(\rho_{e}\right) \sum_{m} r_{m} \frac{d \rho}{d r}\left(r_{m}\right)=0 .
$$

The cohesive energy per atom is given by

$$
-E_{c}^{(a)}=\frac{1}{2} \sum_{m} \varphi\left(r_{m}\right)+F\left(\rho_{e}\right) .
$$

The unrelaxed vacancy formation energy is

$$
\begin{gathered}
-E_{v f}^{(a)}=\frac{1}{2} \sum_{m} \varphi\left(r_{m}\right)-\sum_{m}\left[F\left(\rho_{e}-\rho\left(r_{m}\right)\right)-F\left(\rho_{e}\right)\right] \simeq \\
\simeq \frac{1}{2} \sum_{m} \varphi\left(r_{m}\right)+\frac{\partial F}{\partial \rho}\left(\rho_{e}\right) \sum_{m} \rho\left(r_{m}\right)-\frac{1}{2} \frac{\partial^{2} F}{\partial \rho^{2}}\left(\rho_{e}\right) \sum_{m} \rho^{2}\left(r_{m}\right) .
\end{gathered}
$$

The elastic constants at equilibrium can be also calculated [15] and approximate value of bulk modulus is given by 


$$
\begin{aligned}
B^{(a)}=\frac{1}{9 V_{a}}\left\{\frac{1}{2} \sum_{m}\left(r_{m}^{2} \frac{d^{2} \varphi}{d r^{2}}\left(r_{m}\right)-r_{m} \frac{d \varphi}{d r}\left(r_{m}\right)\right)+\frac{\partial F}{\partial \rho}\left(\rho_{e}\right) \sum_{m}\left(r_{m}^{2} \frac{d^{2} \rho}{d r^{2}}\left(r_{m}\right)-r_{m} \frac{d \rho}{d r}\left(r_{m}\right)\right)+\right. \\
\left.+\frac{\partial^{2} F}{\partial \rho^{2}}\left(\rho_{e}\right)\left(\sum_{m} r_{m} \frac{d \rho}{d r}\left(r_{m}\right)\right)^{2}\right\}
\end{aligned}
$$

where $V_{a}$ is the underformed atomic volume. Parameterization procedure consists of three stages: 1. The set of values of $(\alpha, \beta)$ is specified. For each pair $(\alpha, \beta)$ we calculate the values of $\gamma, \rho_{e}$ $F\left(\rho_{e}\right), F^{\prime}\left(\rho_{e}\right)$ and $F^{\prime \prime}\left(\rho_{e}\right)$ that satisfy condition (11) and the condition

$$
\left(E_{c}-E_{c}^{(a)}\right)^{2}+\left(E_{v f}-E_{v f}^{(a)}\right)^{2}+\left(B-B^{(a)}\right)^{2}=0
$$

2. We choose such pairs $(\alpha, \beta)$ wherein $\gamma>0$ and conditions (6)-(8) are satisfied for $\rho=\rho_{e}$;

3. From the obtained set of pairs we determine the optimal pair $(\alpha, \beta)$ that provides the minimal value of

$$
\left(c_{11}-c_{11}^{(a)}\right)^{2}+\left(c_{12}-c_{12}^{(a)}\right)^{2}+\left(c_{44}-c_{44}^{(a)}\right)^{2}
$$

for bcc and fcc metals or the minimal value of

$$
\left(c_{11}-c_{11}^{(a)}\right)^{2}+\left(c_{12}-c_{12}^{(a)}\right)^{2}+\left(c_{13}-c_{13}^{(a)}\right)^{2}+\left(c_{33}-c_{33}^{(a)}\right)^{2}+\left(c_{44}-c_{44}^{(a)}\right)^{2}
$$

for hcp metals. To calculate coefficients $c_{n}$ of embedding energy function (9) we require nine conditions. First of all we have values of $\rho_{e}, F\left(\rho_{e}\right), F^{\prime}\left(\rho_{e}\right)$ and $F^{\prime \prime}\left(\rho_{e}\right)$ that correspond to the optimal pair $(\alpha, \beta)$. Then we can calculate

$$
c_{0}=F\left(\rho_{e}\right), \quad c_{1}=\rho_{e} \frac{\partial F}{\partial \rho}\left(\rho_{e}\right), \quad c_{2}=\frac{1}{2} \rho_{e}^{2} \frac{\partial^{2} F}{\partial \rho^{2}}\left(\rho_{e}\right) .
$$

Many studies require knowledge of interatomic interaction at distances different from the equilibrium one. Rose it et al. [27] have shown that the total binding energy of most metals, both alloys and elements, as a function of lattice constant can be described by a universal equation:

$$
\begin{gathered}
E\left(a^{*}\right)=f\left(a^{*}\right) \exp \left(-a^{*}\right), \\
a^{*}=\frac{1}{l}\left(r_{W S}-r_{W S E}\right), \quad l=\left(\frac{E_{c}}{12 \pi B r_{W S E}}\right)^{1 / 2},
\end{gathered}
$$

where $f\left(a^{*}\right)$ is a low-order polynomial, $a^{*}$ is a scaled length determined by the radius of WignerSeitz sphere $r_{W S}, r_{W S E}$ and $l$ are equilibrium radius and the length scale, respectively. The values of coefficients $c_{3}, c_{4}$ and $c_{5}$ are so calculated that they provide the best fit to the equation of state (EOS) of Rose et al. [27] when $0.7 a \leqslant$ lattice constant $\leqslant a$. The surface energy is a fundamental property of a metal surface and it is the energy required to create a new surface. The surface energy can be determined by taking the energy difference between the total energy of a periodic slab and an equivalent bulk reference amount:

$$
E_{s f}=\frac{1}{2 S}\left(E_{s l a b}-N \cdot E_{b u l k}\right),
$$

where $E_{\text {slab }}$ is the total energy of an $N$-atom slab, $E_{b u l k}$ is the energy of one atom in the bulk at the lattice constant of the atoms in the interior of the slab $\left(=E_{c}\right), S$ is the area of the slab surface, and the factor $1 / 2$ accounts for the two surfaces in the slab. For simplicity, the calculations were done using the bulk equilibrium lattice parameters, with no relaxation or reconstruction at the surface. We have calculated the formation energies for bulk terminated low index (100), (110) 
and (111) surfaces. It is known that $E_{s f}(111)<E_{s f}(100)<E_{s f}(110)$ for bcc and fcc metals. Then $E_{s f}(100)$ should be close to the average surface energy for polycrystalline solids $E_{s f}$. The values of the last three coefficients $c_{6}, c_{7}$ and $c_{8}$ are so calculated that they satisfy condition $(5)$, condition $\left\langle E_{s f}(100)-E_{s f}\right\rangle / E_{s f} \leqslant 0.05$ and provide the best fit to the equation of state (EOS) of Rose et al. [27] when $a \leqslant$ lattice constant $\leqslant 1.5 a$.

As an illustration the proposed EAM potential functions for $\mathrm{Al}, \mathrm{Fe}$ and $\mathrm{Ti}$ are shown in Figs. 1-3 on page 238. The density in Fig. 3 is scaled by the corresponding equilibrium electron density. Fig. 4 presents the total energy versus lattice constant for $\mathrm{Al}, \mathrm{Fe}$ and Ti for the present model in comparison with the calculated results from the EOS of Rose et al. [27]. The predicted results by the present model are in good agreement with those from the equation of state (12).

\section{Results}

The experimental data used in fitting procedure consist of the equilibrium lattice constant, the cohesive energy, the vacancy formation energy, the bulk modulus and three elastic constants. They are given in Tab. 1-6 and 11. The fitting procedure is performed using a cutoff distance $r_{c}=2 a$ for fcc and bcc metals, and $r_{c}=2 c$ for hcp metals so that the long-range interactions are included.

Table 1. Properties of pure fcc metals used in fitting

\begin{tabular}{|c|c|c|c|c|c|c|c|}
\hline & $\mathrm{a}, \mathrm{A}$ & $E_{c}, \mathrm{eV}$ & $E_{v f}, \mathrm{eV}$ & $\mathrm{B}, \mathrm{eV} / \mathrm{A}^{3}$ & $c_{11}, \mathrm{eV} / \mathrm{A}^{3}$ & $c_{12}, \mathrm{eV} / \mathrm{A}^{3}$ & $c_{44}, \mathrm{eV} / \mathrm{A}^{3}$ \\
\hline $\mathrm{Al}$ & $4.05[15]$ & $3.34[15]$ & $0.64[16]$ & $0.474[20]$ & $0.666[20]$ & $0.377[20]$ & $0.177[20]$ \\
\hline $\mathrm{Ca}$ & $5.58[15]$ & $1.84[15]$ & $0.70[17]$ & $0.133[21]$ & $0.173[21]$ & $0.114[21]$ & $0.102[21]$ \\
\hline $\mathrm{Ni}$ & $3.52[15]$ & $4.44[15]$ & $1.79[18]$ & $1.161[20]$ & $1.548[20]$ & $0.967[20]$ & $0.775[20]$ \\
\hline $\mathrm{Cu}$ & $3.61[15]$ & $3.49[15]$ & $1.28[18]$ & $0.863[22]$ & $1.042[22]$ & $0.754[22]$ & $0.466[22]$ \\
\hline $\mathrm{Pd}$ & $3.89[15]$ & $3.89[15]$ & $1.85[19]$ & $1.205[20]$ & $1.417[20]$ & $1.099[20]$ & $0.447[20]$ \\
\hline $\mathrm{Ag}$ & $4.09[15]$ & $2.95[15]$ & $1.10[18]$ & $0.632[20]$ & $0.763[20]$ & $0.566[20]$ & $0.283[20]$ \\
\hline $\mathrm{Ir}$ & $3.84[15]$ & $6.94[15]$ & $1.97[16]$ & $2.216[23]$ & $3.683[23]$ & $1.554[23]$ & $1.635[23]$ \\
\hline $\mathrm{Pt}$ & $3.92[15]$ & $5.84[15]$ & $1.35[18]$ & $1.765[20]$ & $2.164[20]$ & $1.565[20]$ & $0.478[20]$ \\
\hline $\mathrm{Au}$ & $4.08[15]$ & $3.81[15]$ & $0.90[18]$ & $1.083[20]$ & $1.204[20]$ & $1.022[20]$ & $0.259[20]$ \\
\hline $\mathrm{Pb}$ & $4.95[15]$ & $2.03[15]$ & $0.58[18]$ & $0.279[20]$ & $0.310[20]$ & $0.264[20]$ & $0.094[20]$ \\
\hline
\end{tabular}

Table 2. Parameters of the atomic electron density distribution

\begin{tabular}{|c|c|c|c|}
\hline & $\rho_{0}, \mathrm{e} / \mathrm{A}^{3}$ & $\alpha, 1 / \mathrm{A}$ & $\beta, 1 / \mathrm{A}$ \\
\hline $\mathrm{Al}$ & 11.8189 & 2.0240 & -0.7023 \\
\hline $\mathrm{Ca}$ & 11.1967 & 1.6034 & -0.4968 \\
\hline $\mathrm{Ni}$ & 64.7056 & 2.5152 & -0.7412 \\
\hline $\mathrm{Cu}$ & 61.8709 & 2.4387 & -0.7104 \\
\hline $\mathrm{Pd}$ & 81.8363 & 2.2790 & -0.6496 \\
\hline $\mathrm{Ag}$ & 68.5546 & 2.1650 & -0.6436 \\
\hline $\mathrm{Ir}$ & 15.5880 & 2.7752 & -2.2862 \\
\hline $\mathrm{Pt}$ & 127.2935 & 2.3590 & -0.7700 \\
\hline $\mathrm{Au}$ & 119.0748 & 2.2650 & -0.7220 \\
\hline $\mathrm{Pb}$ & 65.4301 & 1.8120 & -0.5660 \\
\hline
\end{tabular}




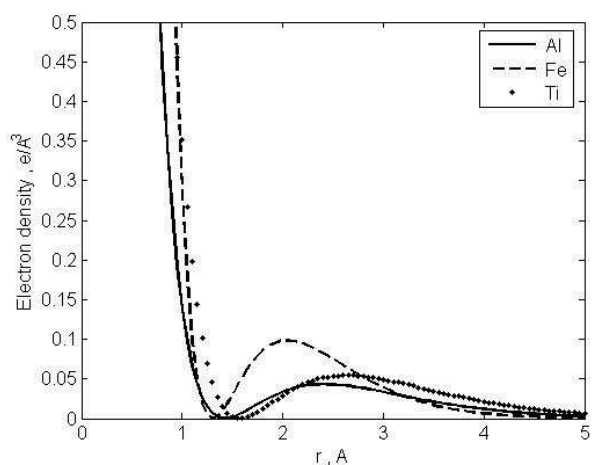

Fig. 1. Electron densities as functions of distance

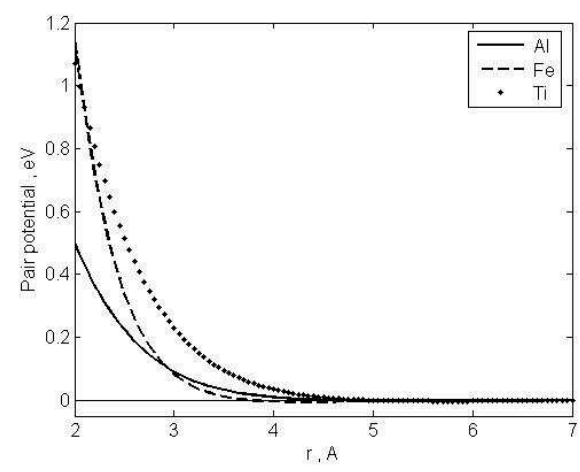

Fig. 2. Pair interaction energies as functions of distance between atoms

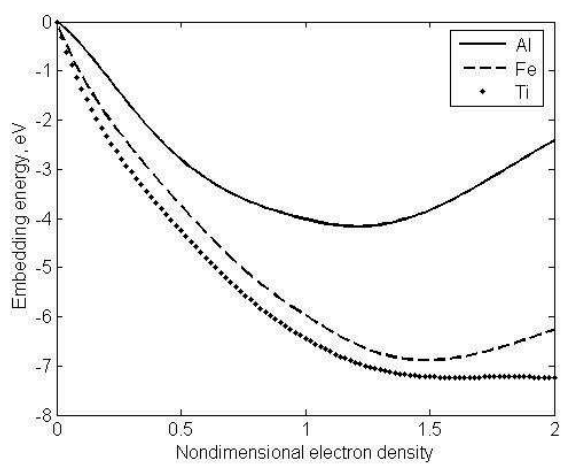

Fig. 3. Embedding energies as functions of non-dimensional background electron density
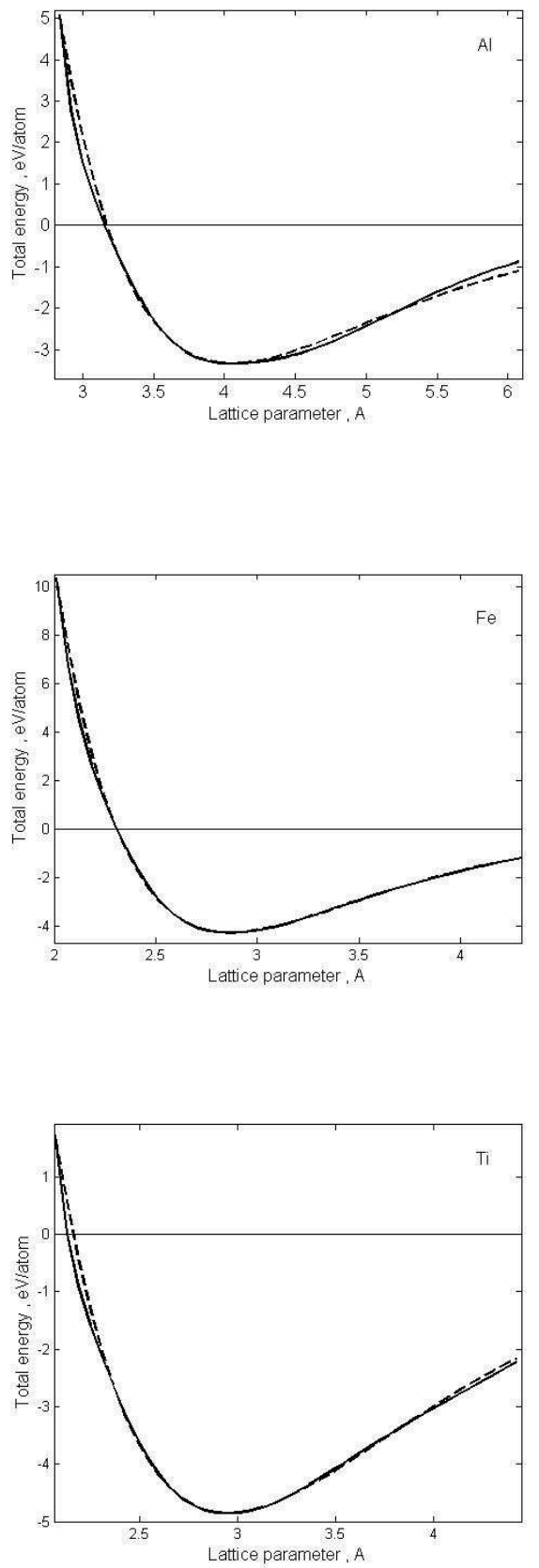

Fig. 4. Equation of state for metals Al, $\mathrm{Fe}$ and $\mathrm{Ti}$. The solid curves are from the present model, and the dashed curves are from EOS of Rose et al [27] 
Table 3. Parameters of pair potential

\begin{tabular}{|c|c|c|c|c|c|}
\hline & $\mathrm{Al}$ & $\mathrm{Ca}$ & $\mathrm{Ni}$ & $\mathrm{Cu}$ & $\mathrm{Pd}$ \\
\hline$\epsilon, \mathrm{eV}$ & 1.1942 & 2.2694 & 5.2908 & 3.5064 & 5.0178 \\
\hline$a_{-1}$ & 1 & 1 & 1 & 1 & 1 \\
\hline$a_{0}$ & 0.2789 & 0.1123 & $4.7257 \mathrm{E}-02$ & $3.3716 \mathrm{E}-02$ & $9.6939 \mathrm{E}-03$ \\
\hline$a_{1}$ & 4.8352 & 4.5452 & 4.1637 & 4.0568 & 3.8375 \\
\hline$a_{2}$ & 0.3980 & 0.4139 & 0.4083 & 0.4058 & 0.4001 \\
\hline$a_{3}$ & $-2.5136 \mathrm{E}-02$ & $-2.6444 \mathrm{E}-02$ & $-2.6100 \mathrm{E}-02$ & $-2.5914 \mathrm{E}-02$ & $-2.5444 \mathrm{E}-02$ \\
\hline$a_{4}$ & $-3.6957 \mathrm{E}-03$ & $-4.6128 \mathrm{E}-03$ & $-5.0168 \mathrm{E}-03$ & $-5.1006 \mathrm{E}-03$ & $-5.2458 \mathrm{E}-03$ \\
\hline$a_{5}$ & $4.7400 \mathrm{E}-04$ & $7.5911 \mathrm{E}-04$ & $8.4373 \mathrm{E}-04$ & $8.5756 \mathrm{E}-04$ & $8.7750 \mathrm{E}-04$ \\
\hline$a_{6}$ & $-9.79774 \mathrm{E}-05$ & $-9.5564 \mathrm{E}-05$ & $-8.9424 \mathrm{E}-05$ & $-8.7614 \mathrm{E}-05$ & $-8.3827 \mathrm{E}-05$ \\
\hline \hline & $\mathrm{Ag}$ & Ir & Pt & Au & Pb \\
\hline$\epsilon, \mathrm{eV}$ & 3.0321 & 54.8862 & 4.3999 & 2.7498 & 1.6215 \\
\hline$a_{-1}$ & 1 & 1 & 1 & 1 & 1 \\
\hline$a_{0}$ & $5.7924 \mathrm{E}-02$ & 0.7359 & 0.1874 & 0.1526 & 0.1236 \\
\hline$a_{1}$ & 4.2404 & 1.4333 & 4.7776 & 4.6934 & 4.5928 \\
\hline$a_{2}$ & 0.4100 & 0.1066 & 0.4112 & 0.4135 & 0.4140 \\
\hline$a_{3}$ & $-2.6214 \mathrm{E}-02$ & $-1.6370 \mathrm{E}-02$ & $-2.6115 \mathrm{E}-02$ & $-2.6338 \mathrm{E}-02$ & $-2.6434 \mathrm{E}-02$ \\
\hline$a_{4}$ & $-4.9504 \mathrm{E}-03$ & $-2.2352 \mathrm{E}-03$ & $-4.1715 \mathrm{E}-03$ & $-4.3713 \mathrm{E}-03$ & $-4.5441 \mathrm{E}-03$ \\
\hline$a_{5}$ & $8.3172 \mathrm{E}-04$ & $-2.3589 \mathrm{E}-04$ & $6.3817 \mathrm{E}-04$ & $6.9646 \mathrm{E}-04$ & $7.4216 \mathrm{E}-04$ \\
\hline$a_{6}$ & $-9.0705 \mathrm{E}-05$ & $-2.3226 \mathrm{E}-05$ & $-9.8622 \mathrm{E}-05$ & $-9.7661 \mathrm{E}-05$ & $-9.6268 \mathrm{E}-05$ \\
\hline
\end{tabular}

Table 4. Parameters of embedding energy function

\begin{tabular}{|c|c|c|c|c|c|}
\hline & $\mathrm{Al}$ & $\mathrm{Ca}$ & $\mathrm{Ni}$ & $\mathrm{Cu}$ & $\mathrm{Pd}$ \\
\hline$\rho_{e}, \mathrm{e} / \mathrm{A}^{3}$ & 0.6071 & 0.2825 & 1.3864 & 1.2873 & 1.5224 \\
\hline$c_{0}, \mathrm{eV}$ & -4.0196 & -2.6178 & -6.2832 & -4.7327 & -5.5288 \\
\hline$c_{1}, \mathrm{eV}$ & -1.2472 & -1.4711 & -3.5972 & -2.4513 & -3.2781 \\
\hline$c_{2}, \mathrm{eV}$ & 1.5546 & 0.1251 & 0.7075 & 1.4285 & 4.2048 \\
\hline$c_{3}, \mathrm{eV}$ & 1.7127 & -2.8157 & 14.4820 & 11.6178 & 32.8210 \\
\hline$c_{4}, \mathrm{eV}$ & 10.2885 & -1.4062 & 47.6636 & 35.5600 & 83.2640 \\
\hline$c_{5}, \mathrm{eV}$ & 7.3580 & 0.388 & 31.2032 & 23.0893 & 52.3971 \\
\hline$c_{6}, \mathrm{eV}$ & 6.8388 & 7.0545 & 16.2018 & 11.2783 & 17.3320 \\
\hline$c_{7}, \mathrm{eV}$ & -8.3183 & -7.8377 & -19.1089 & -13.1025 & -15.1792 \\
\hline$c_{8}, \mathrm{eV}$ & 2.7751 & 2.6050 & 6.7657 & 4.6236 & 4.7505 \\
\hline \hline & $\mathrm{Ag}$ & $\mathrm{Ir}$ & $\mathrm{Pt}$ & $\mathrm{Au}$ & $\mathrm{Pb}$ \\
\hline$\rho_{e}, \mathrm{e} / \mathrm{A}$ & 1.5208 & 2.9282 & 3.4701 & 2.9855 & 1.6884 \\
\hline$c_{0}, \mathrm{eV}$ & -4.0177 & -4.9872 & -7.0594 & -4.5788 & -2.5791 \\
\hline$c_{1}, \mathrm{eV}$ & -2.0716 & $-1.7248 \mathrm{E}-02$ & -2.2656 & -1.4342 & -1.0345 \\
\hline$c_{2}, \mathrm{eV}$ & 1.8795 & $1.6268 \mathrm{E}-05$ & 5.2919 & 4.1205 & 1.7630 \\
\hline$c_{3}, \mathrm{eV}$ & 12.3597 & -12.9772 & 8.3276 & 8.7865 & 3.6147 \\
\hline$c_{4}, \mathrm{eV}$ & 35.3728 & -13.7696 & 25.1362 & 22.7899 & 10.8850 \\
\hline$c_{5}, \mathrm{eV}$ & 22.9465 & -5.7624 & 17.3066 & 14.9793 & 7.4887 \\
\hline$c_{6}, \mathrm{eV}$ & 10.5983 & 7.8483 & 13.1224 & 8.8042 & 5.9092 \\
\hline$c_{7}, \mathrm{eV}$ & -11.0679 & -4.5586 & -10.9029 & -6.7961 & -5.4636 \\
\hline$c_{8}, \mathrm{eV}$ & 3.7000 & 0.6965 & 3.0877 & 1.9187 & 1.6822 \\
\hline
\end{tabular}


Table 5. Calculated and experimental properties of pure metals. The first lines present the experimental values of the three elastic constants (they are used in fitting procedure), average surface energy and the commonly accepted values of vacancy formation energies.

The second lines present the values predicted by the potential

\begin{tabular}{|c|c|c|c|c|c|c|}
\hline & $\begin{array}{c}c_{11}, \\
\mathrm{eV} / \mathrm{A}^{3}\end{array}$ & $\begin{array}{c}c_{12} \\
\mathrm{eV} / \mathrm{A}^{3}\end{array}$ & $\begin{array}{c}c_{44} \\
\mathrm{eV} / \mathrm{A}^{3}\end{array}$ & $\begin{array}{c}\mathrm{B}, \\
\mathrm{eV} / \mathrm{A}^{3}\end{array}$ & $E_{v f}, \mathrm{eV}$ & $\begin{array}{c}\left\langle E_{s f}\right\rangle, E_{s f}(100), \\
\mathrm{J} / \mathrm{m}^{2}\end{array}$ \\
\hline \multirow[t]{2}{*}{$\mathrm{Al}$} & 0.666 & 0.377 & 0.177 & 0.474 & $0.62-0.66[16]$ & $1.143,1.16[16,54]$ \\
\hline & 0.645 & 0.388 & 0.179 & 0.474 & 0.64 & 1.17 \\
\hline \multirow[t]{2}{*}{$\mathrm{Ca}$} & 0.173 & 0.114 & 0.102 & 0.133 & $0.7[17]$ & $0.502,0.49[16,54]$ \\
\hline & 0.213 & 0.093 & 0.086 & 0.13 & 0.70 & 0.51 \\
\hline \multirow[t]{2}{*}{$\mathrm{Ni}$} & 1.548 & 0.967 & 0.775 & 1.161 & $1.6,1.79[18,24]$ & $2.38,2.45[16,54]$ \\
\hline & 1.783 & 0.850 & 0.710 & 1.161 & 1.79 & 2.454 \\
\hline \multirow[t]{2}{*}{$\mathrm{Cu}$} & 1.042 & 0.754 & 0.466 & 0.863 & $1.28,1.3[18,25]$ & $1.79,1.825[16,54]$ \\
\hline & 1.225 & 0.681 & 0.423 & 0.863 & 1.28 & 1.84 \\
\hline \multirow[t]{2}{*}{$\mathrm{Pd}$} & 1.417 & 1.099 & 0.447 & 1.205 & $1.7,1.85[18,19]$ & $2.003,2.05[16,54]$ \\
\hline & 1.565 & 1.025 & 0.431 & 1.205 & 1.85 & 2.06 \\
\hline \multirow[t]{2}{*}{$\mathrm{Ag}$} & 0.763 & 0.566 & 0.283 & 0.632 & $1.1[18,25]$ & $1.246,1.25[16,54]$ \\
\hline & 0.870 & 0.513 & 0.267 & 0.632 & 1.1 & 1.26 \\
\hline \multirow[t]{2}{*}{ Ir } & 3.683 & 1.554 & 1.635 & 2.216 & $1.79,2.27^{a}[18,26]$ & $3.048,3.00[16,54]$ \\
\hline & 3.676 & 1.486 & 1.486 & 2.216 & 1.97 & 3.03 \\
\hline \multirow[t]{2}{*}{$\mathrm{Pt}$} & 2.164 & 1.565 & 0.478 & 1.765 & $1.35,1.5[18,25]$ & $2.489,2.475[16,54]$ \\
\hline & 2.239 & 1.528 & 0.474 & 1.765 & 1.35 & 2.48 \\
\hline \multirow[t]{2}{*}{$\mathrm{Au}$} & 1.204 & 1.022 & 0.259 & 1.083 & $0.89,0.93[18,19]$ & $1.506,1.50[16,54]$ \\
\hline & 1.333 & 0.958 & 0.253 & 1.083 & 0.9 & 1.51 \\
\hline \multirow[t]{2}{*}{$\mathrm{Pb}$} & 0.310 & 0.264 & 0.094 & 0.279 & $0.58[18]$ & $0.593,0.60[16,54]$ \\
\hline & 0.363 & 0.237 & 0.088 & 0.279 & 0.58 & 0.61 \\
\hline
\end{tabular}

\subsection{Results of potential fitting for bcc metals}

In what follows the results of fitting for nine bcc metals are presented. Tab. 7 lists the parameters of the atomic electron density distribution. Parameters of pair potential are listed in Tab. 8. Coefficients of the embedding function $F(\rho)$ are given in Tab. 9.

The calculated properties of pure metals from the proposed potential are compared with the experimental values, to which they were fitted in Tab. 10. The first lines contain the experimental values, while the second lines contain the values predicted by the potential. As the fitting procedure suggests the equilibrium lattice constant, the cohesive energy, the vacancy formation energy and the bulk modulus are reproduced exactly. For softer materials such as Li, Na and K, the average discrepancy between the calculated and experimental values of elastic constants is found to be relatively large. For other metals, the match between experiment and the proposed EAM model is good and the average discrepancy is found to be less than $5 \%$.

Table 6. Properties of pure bcc metals used in fitting

\begin{tabular}{|c|c|c|c|c|c|c|c|}
\hline & $\mathrm{a}, \mathrm{A}$ & $E_{c}, \mathrm{eV}$ & $E_{v f}, \mathrm{eV}$ & $\mathrm{B}, \mathrm{eV} / \mathrm{A}^{3}$ & $c_{11}, \mathrm{eV} / \mathrm{A}^{3}$ & $c_{12}, \mathrm{eV} / \mathrm{A}^{3}$ & $c_{44}, \mathrm{eV} / \mathrm{A}^{3}$ \\
\hline $\mathrm{Li}$ & $3.51[15]$ & $1.65[15]$ & $0.34[28]$ & $0.081[35]$ & $0.09[35]$ & $0.076[35]$ & $0.067[35]$ \\
\hline $\mathrm{Na}$ & $4.29[15]$ & $1.13[15]$ & $0.39[29]$ & $0.045[36]$ & $0.52[36]$ & $0.042[36]$ & $0.032[36]$ \\
\hline $\mathrm{K}$ & $5.34[15]$ & $0.94[15]$ & $0.39[30]$ & $0.023[37]$ & $0.026[37]$ & $0.021[37]$ & $0.018[37]$ \\
\hline $\mathrm{V}$ & $3.03[15]$ & $5.31[15]$ & $2.10[31]$ & $0.97[20]$ & $1.427[20]$ & $0.743[20]$ & $0.277[20]$ \\
\hline
\end{tabular}




\begin{tabular}{|c|c|c|c|c|c|c|c|}
\hline Fe & $2.87[15]$ & $4.28[15]$ & $1.60[32]$ & $1.04[20]$ & $1.440[20]$ & $0.84[20]$ & $0.726[20]$ \\
\hline $\mathrm{Nb}$ & $3.30[15]$ & $7.57[15]$ & $2.75[33]$ & $1.02[20]$ & $1.50[20]$ & $0.784[20]$ & $0.176[20]$ \\
\hline $\mathrm{Mo}$ & $3.147[15]$ & $6.82[15]$ & $3.10[33]$ & $1.62[20]$ & $2.89[20]$ & $0.985[20]$ & $0.680[20]$ \\
\hline $\mathrm{Ta}$ & $3.30[15]$ & $8.10[15]$ & $2.18[5]$ & $1.25[38]$ & $1.66[38]$ & $0.987[38]$ & $0.545[38]$ \\
\hline $\mathrm{W}$ & $3.16[15]$ & $8.90[15]$ & $3.95[34]$ & $1.937[20]$ & $3.26[20]$ & $1.276[20]$ & $1.020[20]$ \\
\hline
\end{tabular}

Table 7. Parameters of the atomic electron density distribution

\begin{tabular}{|c|c|c|c|}
\hline & $\rho_{0}, \mathrm{e} / \mathrm{A}^{3}$ & $\alpha, 1 / \mathrm{A}$ & $\beta, 1 / \mathrm{A}$ \\
\hline $\mathrm{Li}$ & 4.9320 & 2.1860 & -0.5800 \\
\hline $\mathrm{Na}$ & 9.9897 & 1.7900 & -0.4660 \\
\hline $\mathrm{K}$ & 11.9047 & 1.5790 & -0.3950 \\
\hline $\mathrm{V}$ & 104.4650 & 3.0600 & -0.7370 \\
\hline $\mathrm{Fe}$ & 75.1320 & 2.6810 & -0.7661 \\
\hline $\mathrm{Nb}$ & 159.2303 & 2.9080 & -0.6900 \\
\hline $\mathrm{Mo}$ & 198.1089 & 3.0980 & -0.7490 \\
\hline $\mathrm{Ta}$ & 145.5923 & 2.3560 & -0.6600 \\
\hline $\mathrm{W}$ & 301.6596 & 2.9480 & -0.7300 \\
\hline
\end{tabular}

Table 8. Parameters of pair potential

\begin{tabular}{|c|c|c|c|c|c|}
\hline & $\mathrm{Li}$ & $\mathrm{Na}$ & $\mathrm{K}$ & $\mathrm{V}$ & $\mathrm{Fe}$ \\
\hline$\epsilon, \mathrm{eV}$ & 2.061185 & 2.4386 & 5.9982 & 82.1435 & 9.2046 \\
\hline$a_{-1}$ & 1 & 1 & 1 & 1 & 1 \\
\hline$a_{0}$ & -0.0525 & -0.0645 & -0.0837 & -0.0951 & $1.2335 \mathrm{E}-02$ \\
\hline$a_{1}$ & 3.0107 & 2.7788 & 2.2963 & 1.8600 & 3.8637 \\
\hline$a_{2}$ & 0.3724 & 0.3631 & 0.3419 & 0.3202 & 0.4009 \\
\hline$a_{3}$ & $-2.2853 \mathrm{E}-02$ & $-2.1925 \mathrm{E}-02$ & $-1.9725 \mathrm{E}-02$ & $-1.7413 \mathrm{E}-02$ & $-2.5506 \mathrm{E}-02$ \\
\hline$a_{4}$ & $-5.5517 \mathrm{E}-03$ & $-5.5803 \mathrm{E}-03$ & $-5.5636 \mathrm{E}-03$ & $-5.4548 \mathrm{E}-03$ & $-5.2300 \mathrm{E}-03$ \\
\hline$a_{5}$ & $8.8403 \mathrm{E}-04$ & $8.7147 \mathrm{E}-04$ & $8.2895 \mathrm{E}-04$ & $7.7261 \mathrm{E}-04$ & $8.7564 \mathrm{E}-04$ \\
\hline$a_{6}$ & $-6.9006 \mathrm{E}-05$ & $-6.4744 \mathrm{E}-05$ & $-5.5766 \mathrm{E}-05$ & $-4.7535 \mathrm{E}-05$ & $-8.4284 \mathrm{E}-05$ \\
\hline \hline & Nb & Mo & Ta & W & \\
\hline$\epsilon, \mathrm{eV}$ & 154.6293 & 193.6024 & 12.9004 & 151.8057 & \\
\hline$a_{-1}$ & 1 & 1 & 1 & 1 & \\
\hline$a_{0}$ & -0.9793 & -0.9426 & $-7.7812 \mathrm{E}-03$ & $-8.7430 \mathrm{E}-02$ & \\
\hline$a_{1}$ & 1.6977 & 1.9024 & 3.6497 & 2.1763 & \\
\hline$a_{2}$ & 0.3114 & 0.3224 & 0.3946 & 0.3362 & \\
\hline$a_{3}$ & $-1.6469 \mathrm{E}-02$ & $-1.7652 \mathrm{E}-02$ & $-2.4962 \mathrm{E}-02$ & $-1.9120 \mathrm{E}-02$ & \\
\hline$a_{4}$ & $-5.3892 \mathrm{E}-03$ & $-5.4695 \mathrm{E}-03$ & $-5.3458 \mathrm{E}-03$ & $-5.5429 \mathrm{E}-03$ & \\
\hline$a_{5}$ & $7.4734 \mathrm{E}-04$ & $7.7881 \mathrm{E}-04$ & $8.8735 \mathrm{E}-04$ & $8.1513 \mathrm{E}-04$ & \\
\hline$a_{6}$ & $-4.4443 \mathrm{E}-05$ & $-4.8338 \mathrm{E}-05$ & $-8.0524 \mathrm{E}-05$ & $-5.3513 \mathrm{E}-05$ & \\
\hline
\end{tabular}

Table 9. Parameters of embedding energy function

\begin{tabular}{|c|c|c|c|c|c|}
\hline & $\mathrm{Li}$ & $\mathrm{Na}$ & $\mathrm{K}$ & $\mathrm{V}$ & $\mathrm{Fe}$ \\
\hline$\rho_{e}, \mathrm{e} / \mathrm{A}^{3}$ & 0.0512 & 0.09536 & 0.0686 & 0.3435 & 1.0427 \\
\hline
\end{tabular}




\begin{tabular}{|c|c|c|c|c|c|}
\hline$c_{0}, \mathrm{eV}$ & -1.9735 & -1.4880 & -1.3246 & -7.3118 & -5.9779 \\
\hline$c_{1}, \mathrm{eV}$ & -0.6574 & -0.7400 & -0.7697 & -4.0071 & -3.2790 \\
\hline$c_{2}, \mathrm{eV}$ & 0.1063 & 0.1416 & 0.0765 & 1.3299 & 0.3189 \\
\hline$c_{3}, \mathrm{eV}$ & -10.5307 & -3.6949 & -1.5679 & -13.9586 & -9.6004 \\
\hline$c_{4}, \mathrm{eV}$ & -25.9305 & -8.9704 & -4.0784 & -36.6665 & -15.2388 \\
\hline$c_{5}, \mathrm{eV}$ & -16.6095 & -5.8820 & -2.9890 & -24.6826 & -8.0182 \\
\hline$c_{6}, \mathrm{eV}$ & 0.81 & 0.6017 & -0.0436 & -1.9572 & 9.9234 \\
\hline$c_{7}, \mathrm{eV}$ & -1.1659 & -0.8135 & -0.0406 & 1.4516 & -10.4948 \\
\hline$c_{8}, \mathrm{eV}$ & 0.4366 & 0.3067 & 0.0152 & -0.3653 & 3.3785 \\
\hline \hline & $\mathrm{Nb}$ & $\mathrm{Mo}$ & $\mathrm{Ta}$ & $\mathrm{W}$ & \\
\hline$\rho_{e}, \mathrm{e} / \mathrm{A}$ & 0.4181 & 0.5157 & 1.7998 & 1.0802 & \\
\hline$c_{0}, \mathrm{eV}$ & -10.0954 & -9.7242 & -10.2274 & -12.8561 & \\
\hline$c_{1}, \mathrm{eV}$ & -5.1378 & -5.9440 & -4.1311 & -7.8513 & \\
\hline$c_{2}, \mathrm{eV}$ & 1.8751 & 0.8068 & 2.9597 & 0.7619 & \\
\hline$c_{3}, \mathrm{eV}$ & -15.3758 & -6.7596 & -18.4551 & 2.3567 & \\
\hline$c_{4}, \mathrm{eV}$ & -44.4385 & -15.0462 & -37.2274 & 8.1014 & \\
\hline$c_{5}, \mathrm{eV}$ & -32.1451 & -11.2600 & -21.9090 & 1.5018 & \\
\hline$c_{6}, \mathrm{eV}$ & -3.3407 & 1.6791 & 11.5807 & 4.3212 & \\
\hline$c_{7}, \mathrm{eV}$ & 2.2848 & -1.3272 & -11.6852 & -3.5853 & \\
\hline$c_{8}, \mathrm{eV}$ & -0.5279 & 0.2945 & 3.7310 & 0.8843 & \\
\hline
\end{tabular}

Table 10. Calculated and experimental properties of pure metals. The first lines present the experimental values of the three elastic constants (they are used in fitting procedure, average surface energy and the commonly accepted values of vacancy formation energies.

The second lines present the values predicted by the potential

\begin{tabular}{|c|c|c|c|c|c|c|}
\hline & $\begin{array}{c}c_{11}, \\
\mathrm{eV} / \mathrm{A}^{3}\end{array}$ & $\begin{array}{c}c_{12}, \\
\mathrm{eV} / \mathrm{A}^{3}\end{array}$ & $\begin{array}{c}c_{44}, \\
\mathrm{eV} / \mathrm{A}^{3}\end{array}$ & $\begin{array}{c}\mathrm{B}, \\
\mathrm{eV} / \mathrm{A}^{3}\end{array}$ & $\begin{array}{c}E_{v f}, \\
\mathrm{eV}\end{array}$ & $\begin{array}{c}\left\langle E_{s f}\right\rangle, E_{s f}(100), \\
\mathrm{J} / \mathrm{m}^{2}\end{array}$ \\
\hline $\mathrm{Li}$ & 0.090 & 0.076 & 0.067 & 0.081 & $0.34,0.4[28,39]$ & $0.52,0.525[16,54]$ \\
& 0.115 & 0.064 & 0.051 & 0.081 & 0.34 & 0.51 \\
\hline $\mathrm{Na}$ & 0.052 & 0.042 & 0.032 & 0.045 & $0.36,0.39[29,40]$ & $0.261,0.26[16,54]$ \\
& 0.061 & 0.037 & 0.028 & 0.045 & 0.39 & 0.27 \\
\hline $\mathrm{K}$ & 0.026 & 0.021 & 0.018 & 0.023 & $0.35,0.39[30,41]$ & $0.145,0.13[16,54]$ \\
& 0.033 & 0.018 & 0.014 & 0.023 & 0.39 & 0.14 \\
\hline $\mathrm{V}$ & 1.427 & 0.743 & 0.277 & 0.97 & $2.1,2.2[18,31]$ & $2.622,2.55[16,54]$ \\
& 1.422 & 0.744 & 0.278 & 0.97 & 2.1 & 2.606 \\
\hline $\mathrm{Fe}$ & 1.440 & 0.84 & 0.726 & 1.04 & $1.6,1.79[32,33]$ & $2.42,2.475[16,54]$ \\
& 1.608 & 0.755 & 0.676 & 1.04 & 1.6 & 2.48 \\
\hline $\mathrm{Nb}$ & 1.50 & 0.784 & 0.176 & 1.02 & $2.75,2.7-3.0[18,33]$ & $2.655,2.70[16,54]$ \\
& 1.56 & 0.750 & 0.175 & 1.02 & 2.75 & 2.73 \\
\hline $\mathrm{Mo}$ & 2.89 & 0.985 & 0.680 & 1.62 & $3.0,3.1[18,33]$ & $2.907,3.00[16,54]$ \\
& 2.88 & 0.987 & 0.676 & 1.62 & 3.1 & 3.05 \\
\hline $\mathrm{Ta}$ & 1.66 & 0.987 & 0.545 & 1.25 & $2.18,3.1[5,18]$ & $2.902,3.15[16,54]$ \\
& 1.69 & 1.02 & 0.540 & 1.25 & 2.18 & 3.08 \\
\hline $\mathrm{W}$ & 3.26 & 1.276 & 1.02 & 1.937 & $3.95,3.6-4.1[18,34]$ & $3.27,3.675[[16,54]]$ \\
& 3.28 & 1.266 & 1.02 & 1.937 & 3.95 & 3.57 \\
\hline
\end{tabular}




\subsection{Results of potential fitting for hcp metals}

In what follows the results of fitting for eight hcp metals are presented. Tab. 12 lists the parameters of the atomic electron density distribution. Parameters of pair potential are listed in Tab 13. Coefficients of the embedding function $\mathrm{F}(\mathrm{r})$ are given in Tab. 14.

The calculated properties of pure metals from the proposed potential are compared with the experimental values, to which they were fitted in Tab. 15. The first lines contain the experimental values, while the second lines contain the values predicted by the potential. As the fitting procedure suggests the equilibrium lattice constant, the cohesive energy, the vacancy formation energy and the bulk modulus are reproduced exactly. For such materials as Sc, Ta and Y, the errors are found to be relatively large. As for other metals, the match between experiment and the proposed EAM model is generally satisfactory and the average discrepancy is found to be less than 10\%. Generally, if we consider the match between experimental and calculated results for hcp metals then it is worse in comparison with the results obtained for bcc and fcc metals. This is due to reasons discussed in Introduction.

Table 11. Properties of pure hcp metals used in fitting

\begin{tabular}{|c|c|c|c|c|}
\hline & $\mathrm{Mg}$ & $\mathrm{Sc}$ & $\mathrm{Ti}$ & $\mathrm{Co}$ \\
\hline $\mathrm{a}, \mathrm{A}$ & $3.21[15]$ & $3.31[15]$ & $2.95[15]$ & $2.51[15]$ \\
\hline $\mathrm{c}, \mathrm{A}$ & $5.21[15]$ & $5.27[15]$ & $4.68[15]$ & $4.07[15]$ \\
\hline$E_{c}, \mathrm{eV}$ & $1.53[15]$ & $3.93[15]$ & $4.856[15]$ & $4.387[15]$ \\
\hline$E_{v f}, \mathrm{eV}$ & $0.58[42]$ & $1.15[12]$ & $1.41[43,44]$ & $1.35[12]$ \\
\hline $\mathrm{B}, \mathrm{eV} / \mathrm{A}^{3}$ & $0.22[20]$ & $0.348[49]$ & $0.672[50]$ & $1.17[49]$ \\
\hline$c_{11}, \mathrm{eV} / \mathrm{A}^{3}$ & $0.37[20]$ & $0.618[49]$ & $1.021[50]$ & $1.84[49]$ \\
\hline$c_{12}, \mathrm{eV} / \mathrm{A}^{3}$ & $0.16[20]$ & $0.250[49]$ & $0.576[50]$ & $0.99[49]$ \\
\hline$c_{13}, \mathrm{eV} / \mathrm{A}^{3}$ & $0.136[20]$ & $0.181[49]$ & $0.424[50]$ & $0.69[49]$ \\
\hline$c_{33}, \mathrm{eV} / \mathrm{A}^{3}$ & $0.384[20]$ & $0.668[49]$ & $1.156[50]$ & $2.09[49]$ \\
\hline$c_{44}, \mathrm{eV} / \mathrm{A}^{3}$ & $0.102[20]$ & $0.175[49]$ & $0.294[50]$ & $0.44[49]$ \\
\hline \hline & $\mathrm{Y}$ & $\mathrm{Zr}$ & $\mathrm{Hf}$ & $\mathrm{T}]$ \\
\hline $\mathrm{a}, \mathrm{A}$ & $3.65[15]$ & $3.23[15]$ & $3.19[15]$ & $3.46[15]$ \\
\hline $\mathrm{c}, \mathrm{A}$ & $5.73[15]$ & $5.15[15]$ & $5.05[15]$ & $5.52[15]$ \\
\hline$E_{c}, \mathrm{eV}$ & $4.387[15]$ & $6.316[15]$ & $6.35[15]$ & $1.87[15]$ \\
\hline$E_{v f}, \mathrm{eV}$ & $1.25[12]$ & $1.75[45,46]$ & $2.45[47]$ & $0.52[48]$ \\
\hline $\mathrm{B}, \mathrm{eV} / \mathrm{A}^{3}$ & $0.264[51]$ & $0.595[52]$ & $0.680[49]$ & $0.223[53]$ \\
\hline$c_{11}, \mathrm{eV} / \mathrm{A}^{3}$ & $0.52[51]$ & $0.896[52]$ & $1.187[49]$ & $0.255[53]$ \\
\hline$c_{12}, \mathrm{eV} / \mathrm{A}^{3}$ & $0.182[51]$ & $0.453[52]$ & $0.465[49]$ & $0.221[53]$ \\
\hline$c_{13}, \mathrm{eV} / \mathrm{A}^{3}$ & $0.119[51]$ & $0.406[52]$ & $0.409[49]$ & $0.181[53]$ \\
\hline$c_{33}, \mathrm{eV} / \mathrm{A}^{3}$ & $0.500[51]$ & $1.023[52]$ & $1.276[49]$ & $0.329[53]$ \\
\hline$c_{44}, \mathrm{eV} / \mathrm{A}^{3}$ & $0.168[51]$ & $0.200[52]$ & $0.375[49]$ & $0.045[53]$ \\
\hline
\end{tabular}

Table 12. Parameters of the atomic electron density distribution

\begin{tabular}{|c|c|c|c|}
\hline & $\rho_{0}, \mathrm{e} / \mathrm{A}^{3}$ & $\alpha, 1 / \mathrm{A}$ & $\beta, 1 / \mathrm{A}$ \\
\hline $\mathrm{Mg}$ & 9.0989 & 1.8290 & -0.5980 \\
\hline $\mathrm{Sc}$ & 8.9626 & 1.6300 & -0.5920 \\
\hline $\mathrm{Ti}$ & 17.4479 & 1.8900 & -0.6350 \\
\hline $\mathrm{Co}$ & 61.1899 & 2.5140 & -0.7520 \\
\hline $\mathrm{Y}$ & 61.4080 & 2.1480 & -0.5500 \\
\hline $\mathrm{Zr}$ & 51.1438 & 2.0200 & -0.5520 \\
\hline
\end{tabular}




\begin{tabular}{|c|c|c|c|}
\hline Hf & 126.1746 & 2.2320 & -0.5900 \\
\hline $\mathrm{Tl}$ & 52.9236 & 1.6640 & -0.5000 \\
\hline
\end{tabular}

Table 13. Parameters of pair potential

\begin{tabular}{|c|c|c|c|c|}
\hline & $\mathrm{Mg}$ & $\mathrm{Sc}$ & $\mathrm{Ti}$ & $\mathrm{Co}$ \\
\hline$\epsilon, \mathrm{eV}$ & 1.1679 & 1.7117 & 2.0822 & 3.9685 \\
\hline$a_{-1}$ & 1 & 1 & 1 & 1 \\
\hline$a_{0}$ & 0.1899 & 0.3455 & 0.2306 & 0.0657 \\
\hline$a_{1}$ & 4.7822 & 4.7477 & 4.8324 & 4.2924 \\
\hline$a_{2}$ & 0.4110 & 0.3825 & 0.4062 & 0.4108 \\
\hline$a_{3}$ & $-2.6095 \mathrm{E}-02$ & $-2.4199 \mathrm{E}-02$ & $-2.5711 \mathrm{E}-02$ & $-2.6280 \mathrm{E}-02$ \\
\hline$a_{4}$ & $-4.1576 \mathrm{E}-03$ & $-3.3991 \mathrm{E}-03$ & $-3.9373 \mathrm{E}-03$ & $-4.9020 \mathrm{E}-03$ \\
\hline$a_{5}$ & $6.3391 \mathrm{E}-04$ & $3.4979 \mathrm{E}-04$ & $5.6213 \mathrm{E}-04$ & $8.2249 \mathrm{E}-04$ \\
\hline$a_{6}$ & $-9.8663 \mathrm{E}-05$ & $-9.4998 \mathrm{E}-05$ & $-9.8852 \mathrm{E}-05$ & $-9.1563 \mathrm{E}-05$ \\
\hline & Y & Zr & Hf & Tl \\
\hline$\epsilon, \mathrm{eV}$ & 23.8608 & 6.4257 & 19.7289 & 0.7036 \\
\hline$a_{-1}$ & 1 & 1 & 1 & 1 \\
\hline$a_{0}$ & -0.0735 & -0.0301 & -0.0550 & 0.0714 \\
\hline$a_{1}$ & 2.5764 & 3.3649 & 2.9653 & 4.3289 \\
\hline$a_{2}$ & 0.3546 & 0.3853 & 0.3706 & 0.4114 \\
\hline$a_{3}$ & $-2.1046 \mathrm{E}-02$ & $-2.4106 \mathrm{E}-02$ & $-2.2677 \mathrm{E}-02$ & $-2.6321 \mathrm{E}-02$ \\
\hline$a_{4}$ & $-5.5860 \mathrm{E}-03$ & $-5.4616 \mathrm{E}-03$ & $-5.5592 \mathrm{E}-03$ & $-4.8661 \mathrm{E}-03$ \\
\hline$a_{5}$ & $8.5624 \mathrm{E}-04$ & $8.9212 \mathrm{E}-04$ & $8.8199 \mathrm{E}-04$ & $8.1536 \mathrm{E}-04$ \\
\hline$a_{6}$ & $-6.0996 \mathrm{E}-05$ & $-7.5436 \mathrm{E}-05$ & $-6.8173 \mathrm{E}-05$ & $-9.2160 \mathrm{E}-05$ \\
\hline & & & &
\end{tabular}

Table 14. Parameters of embedding energy function

\begin{tabular}{|c|c|c|c|c|}
\hline & $\mathrm{Mg}$ & $\mathrm{Sc}$ & $\mathrm{Ti}$ & $\mathrm{Co}$ \\
\hline$\rho_{e}, \mathrm{e} / \mathrm{A}^{3}$ & 0.3615 & 0.6972 & 0.9203 & 1.3680 \\
\hline$c_{0}, \mathrm{eV}$ & -2.1730 & -5.3722 & -6.4410 & -5.7471 \\
\hline$c_{1}, \mathrm{eV}$ & -1.1996 & -2.5796 & -2.9289 & -2.6172 \\
\hline$c_{2}, \mathrm{eV}$ & 0.5061 & 0.3228 & 1.6350 & 1.7910 \\
\hline$c_{3}, \mathrm{eV}$ & -10.5844 & -10.8212 & -8.9633 & -11.4124 \\
\hline$c_{4}, \mathrm{eV}$ & -25.5821 & -20.6288 & -18.8240 & -28.4863 \\
\hline$c_{5}, \mathrm{eV}$ & -15.4650 & -12.2774 & -11.7378 & -18.4127 \\
\hline$c_{6}, \mathrm{eV}$ & 2.1772 & 7.0366 & 5.2336 & 1.5758 \\
\hline$c_{7}, \mathrm{eV}$ & -2.7321 & -9.4380 & -7.4424 & -1.8760 \\
\hline$c_{8}, \mathrm{eV}$ & 0.9453 & 3.3412 & 2.6969 & 0.5993 \\
\hline \hline & $\mathrm{Y}$ & $\mathrm{Zr}$ & $\mathrm{Hf}$ & $\mathrm{Tl}$ \\
\hline$\rho_{e}, \mathrm{e} / \mathrm{A}^{3}$ & 0.3456 & 0.7212 & 1.1647 & 1.6113 \\
\hline$c_{0}, \mathrm{eV}$ & -5.6922 & -7.8750 & -8.8098 & -2.2974 \\
\hline$c_{1}, \mathrm{eV}$ & -2.5550 & -3.1711 & -4.8883 & -0.8454 \\
\hline$c_{2}, \mathrm{eV}$ & $2.5624 \mathrm{E}-03$ & 2.6298 & 0.3551 & 2.4945 \\
\hline$c_{3}, \mathrm{eV}$ & -29.3197 & -23.3250 & -31.8673 & 1.2063 \\
\hline$c_{4}, \mathrm{eV}$ & -71.7834 & -63.7504 & -78.3001 & -1.8342 \\
\hline$c_{5}, \mathrm{eV}$ & -45.5983 & -42.4995 & -49.9992 & -1.9980 \\
\hline
\end{tabular}




\begin{tabular}{|c|c|c|c|c|}
\hline$c_{6}, \mathrm{eV}$ & -0.0985 & -2.8443 & 0.1694 & -2.5204 \\
\hline$c_{7}, \mathrm{eV}$ & -0.2879 & 3.8680 & -0.8856 & 3.6203 \\
\hline$c_{8}, \mathrm{eV}$ & 0.0884 & -1.6212 & 0.3690 & -1.5656 \\
\hline
\end{tabular}

Table 15. Calculated and experimental properties of pure metals. The first lines present the experimental values of the five elastic constants (they are used in fitting procedure), average surface energy and the commonly accepted values of vacancy formation energies.

The second lines present the values predicted by the potential

\begin{tabular}{|c|c|c|c|c|c|c|c|}
\hline & $\begin{array}{c}c_{11}, \\
\mathrm{eV} / \mathrm{A}^{3}\end{array}$ & $\begin{array}{c}c_{12}, \\
\mathrm{eV} / \mathrm{A}^{3}\end{array}$ & $\begin{array}{c}c_{13}, \\
\mathrm{eV} / \mathrm{A}^{3}\end{array}$ & $\begin{array}{c}c_{33}, \\
\mathrm{eV} / \mathrm{A}^{3}\end{array}$ & $\begin{array}{c}c_{44}, \\
\mathrm{eV} / \mathrm{A}^{3}\end{array}$ & $E_{v f}, \mathrm{eV}$ & $\left\langle E_{s f}\right\rangle, E_{s f}(0001)$, \\
& 0.370 & 0.160 & 0.136 & 0.384 & 0.102 & $0.58[42]$ & $0.785,0.76[16,54]$ \\
$\mathrm{Mg}$ & 0.365 & 0.153 & 0.142 & 0.377 & 0.106 & 0.58 & 0.78 \\
\hline $\mathrm{Sc}$ & 0.618 & 0.250 & 0.181 & 0.668 & 0.175 & $1.15[12]$ & $1.275[16]$ \\
& 0.613 & 0.221 & 0.207 & 0.634 & 0.195 & 1.15 & 1.318 \\
\hline $\mathrm{Ti}$ & 1.021 & 0.576 & 0.424 & 1.156 & 0.294 & $1.27,1.55[43,44]$ & $1.989,2.10[16,54]$ \\
& 1.080 & 0.479 & 0.454 & 1.113 & 0.301 & 1.41 & 2.09 \\
\hline $\mathrm{Co}$ & 1.840 & 0.990 & 0.690 & 2.090 & 0.440 & $1.35[12]$ & $2.522,2.55[16,54]$ \\
& 1.834 & 0.862 & 0.810 & 1.897 & 0.485 & 1.35 & 2.55 \\
\hline $\mathrm{Y}$ & 0.520 & 0.182 & 0.119 & 0.500 & 0.168 & $1.25[12]$ & $1.125[16]$ \\
& 0.464 & 0.155 & 0.159 & 0.498 & 0.155 & 1.25 & 1.126 \\
\hline $\mathrm{Zr}$ & 0.896 & 0.453 & 0.406 & 1.023 & 0.200 & $>1.5,2.07^{a}[45,46]$ & $1.909,2.0[16,54]$ \\
& 0.885 & 0.460 & 0.435 & 0.924 & 0.212 & 1.75 & 2.02 \\
\hline $\mathrm{Hf}$ & 1.187 & 0.465 & 0.409 & 1.276 & 0.375 & $2.45 \pm 0.2[47]$ & $2.193,2.15[16,54]$ \\
& 1.178 & 0.423 & 0.411 & 1.275 & 0.377 & 2.45 & 2.196 \\
\hline $\mathrm{Tl}$ & 0.255 & 0.221 & 0.181 & 0.329 & 0.045 & $0.52[48]$ & $0.6,0.575[16,54]$ \\
& 0.286 & 0.196 & 0.188 & 0.287 & 0.045 & 0.52 & 0.6 \\
\hline
\end{tabular}

$a$ - result of $a b$ initio calculations

\section{Summary}

This paper presents parameters of a new EAM potential model to describe pure metals. The potential model has a simple function form and it is easy to use in computer simulations. The potential parameters were determined by fitting the pure metal bulk properties: equilibrium lattice constant, the cohesive energy, the bulk modulus, the vacancy formation energy and elastic constants. The fitting procedure has been applied to 27 metals (10 fcc metals, 9 bcc metals and 8 hcp metals). The equilibrium lattice constant, the cohesive energy, the bulk modulus and the vacancy formation energy are reproduced exactly. The agreement between the calculated elastic constants and the experimental data is good. The pair potentials for all metals include long-range interactions. Metal embedding energies have a positive curvature that is in line with first-principles calculations. For all metals, the calculated relation between total energy and lattice constant is in good agreement with that obtained from the equation of state of Rose et al. One common problem with the EAM is that this method often underestimates the surface energies. In the current work, we see improvement of the newly developed potentials over previous EAM models in describing surface energies.

The theory of dynamic bonding [55] suggests that electrons in metals are not free but they are rather tightly bound to the atoms. Then we can assume that the form of electron density dis- 
tribution of a metal atom depends only slightly on surrounding atoms. As a first approximation, one can assume that the embedding energy function is the unique property of an atom because it depends only on electron density due to all other atoms. Then the proposed potential for pure metals allows one to create extensive interaction parameters database for binary systems. All one need to do is to fit the parameters of pair cross-interaction functions against experimental or ab initio data for the relevant alloy system.

The proposed EAM potentials are believed to find applications in diverse areas of materials science and engineering.

\section{References}

[1] M.S.Daw, M.I.Baskes, Semiempirical, quantum mechanical calculation of hydrogen embrittlement in metals, Phys. Rev. Letters, 50(1983), no. 17, 1285.

[2] M.S.Daw, M.I.Baskes, Embedded-atom method: Derivation and application to impurities, surfaces, and other defects in metals, Phys. Rev. B, 29(1983), 6443.

[3] H.W.Sheng, M.J.Kramer, A.Cadien, T.Fujita, M.W.Chen, Highly optimized embeddedatom-method potentials for fourteen fcc metals, Phys. Rev. B, 83(2011), no. 13, 134118.

[4] I.A.Hijazi, Y.H.Park, Consistent analytic embedded atom potential for face-centered cubic metals and alloys, J. Mater. Sci. Technol, 25(2009), no. 6, 835-846.

[5] X.D.Dai, Y.Kong, J.H.Li, B.X.Lin, Extended Finnis-Sinclair potential for bcc and fcc metals and alloys, J. Phys.: Condensed Metter, 18(2006), 4527.

[6] B-J.Lee, M.I.Baskes, H.Kim, Y.K.Cho, Second nearest-neighbor modified embedded atom method potentials for bcc transition metals, Phys. Rev. B , 64(2001), 184102.

[7] S.J.Plimpton, A.P.Thompson, Computational aspects of many-body potentials MRS Bulletin 37(2012), no. 5, 513-521.

[8] R.B.Wilson, D.M.Riffe, An embedded-atom-method model for alkali-metal vibrations, $J$. Phys.: Condens. Matter, 24(2012), 335401.

[9] R.Pasianot, E.J.Savino, Embedded-atom-method interatomic potentials for hcp metals, Phys. Rev. B, 45(1992), 12704-12710.

[10] F.Cleri, V.Rosato, Tight-binding potentials for transition metals and alloys Phys. Rev. B, 48(1993), 22-33.

[11] S.Chen, J.Xu, H.Zhang, A new scheme of many-body potentials for hcp metals, Computational Materials Science, 29(2004), 428-436.

[12] M.I.Baskes, R.A.Johnson, Modified embedded atom potentials for hcp metals, Model. Simul. Mater. Sci. Eng, 2(1994), 147-163.

[13] L.D.Landau, E.M.Lifshitzm, Course of Theoretical Physics. Quantum Mechanics: NonRelativistic Theory, Vol 3, Oxford: Pergamon Press, 1977.

[14] S.M.Foiles, M.I.Baskes, M.S.Daw, Embedded-atom-method functions for the fcc metals Cu, Ag, Au, Ni, Pd, Pt, and their alloys, Phys Rev B, 33(1986), no. 12, 7983.

[15] C.Kittel, Introduction to solid state physics, New York, Wiley, 1996. 
[16] F.R. de Boer, R.Boom, W.C.M.Mattens, A.R.Miedema, A.K.Niessen, Cohesion in metals, Vol. 1, Amsterdam, North Holland, 1988.

[17] P.Ziesche, J.P.Perdew, and C.Fiolhais, Spherical voids in the stabilized jellium model: Rigorous theorems and Pad? representation of the void-formation energy, Phys. Rev. B, 49(1994), no. $12,7916-7928$.

[18] P.Ehrhart, P.Jung, H.Schultz, H.Ullmaier, Atomic defects in metals, edited by H. Ullmaier, Landolt-Bernstein, New series, Group III/25, Berlin, Springer-Verlag, 1991.

[19] H-E.Schaefer , Investigation of thermal equilibrium vacancies in metals by positron annihilation, Phys. Status Solidi A, 102(1987), no. 1, 4-65.

[20] H.Ledbetter, S.Kim, Monocrystal elastic constants and. derived properties of the cubic and the hexagonal elements, in: Handbook of elastic properties of solids, liquids, and gases, Vol. 2, Academic Press, 2001.

[21] P.Sisoda, M.P.Verma, Shear moduli of polycrystalline cubic elements, J. Phys. Chem. Solids, 50(1989), 223-224.

[22] H.Ogi, H. Ledbetter, S. Kim, M. Hirao, Contactless mode-selective resonance ultrasound spectroscopy: electromagnetic acoustic resonance, J. Acoust. Soc. Am, 106(1999), 660-665.

[23] R.O.Simmons, H.Wang, Single crystal elastic constants and calculated aggregate properties: a Handbook, Cambridge MA: MIT Press, 1977.

[24] W.Wycisk, M.Feller-Kniepmeier, Quenching experiments in high purity Ni, J. Nucl. Mater, 69/70(1978), 616-619.

[25] R.W.Balluffi, Vacancy defect mobilities and binding energies obtained from annealing studies, J. Nucl. Mater, 69/70(1978), 240-263.

[26] P.A.Korzhavyi, I.A.Abrikosov, B.Johansson, A.V.Ruban, H.L.Skriver, First-principles calculations of the vacancy formation energy in transition and noble metals, Phys. Rev. B, 59(1999), no. 18, 11693-11703.

[27] J.H.Rose, J.R.Smith, F.Guinea, J.Ferrante, Universal features of the equation of state of metals, Phys. Rev. B, 29(1984), 2963-2969.

[28] R.Feder, Equilibrium defect concentration in crystalline lithium, Phys. Rev. B, 2(1970), no. 4,828 .

[29] R.Feder, H.P.Charbnau, Equilibrium defect concentration in crystalline sodium, Phys. Rev., 149(1966), no. ,2 464.

[30] D.K.C.MacDonald, Self diffusion in the alkali metals, J. Chem. Phys., 21(1953), no. 1, 177.

[31] C.Janot, B.George, P.Delcroix, Point defects in vanadium investigated by Mossbauer spectroscopy and positron annihilation, J. Phys. F: Met. Phys., 12(1982), no. 1, 47.

[32] M.Puska, M.Nieminen, Point defects in solids, in: Density functional methods in chemistry and materials science, edited by M. Springborg, New York, Wiley, 1997.

[33] K.Maier, M.Peo, B.Saile, S.H.Ehaefer, A.Seeger, High-temperature positron annihilation and vacancy formation in refractory metals, Phil. Mag. A, 40(1979), no. 5, 701.

[34] B.J.Lee, M.I.Baskes, H.Kim, Y.K.Cho, Second nearest-neighbor modified embedded atom method potentials for bcc transition metals, Phys. Rev. B, 64(2001), no. 18, 184102. 
[35] R.A.Felice, J.Trivisonno, D.E.Shuele, Temperature and pressure dependence of the singlecrystal elastic constants of ${ }^{6} \mathrm{Li}$ and natural lithium, Phys. Rev. B, 16(1977), no. 12, 5173.

[36] R.H.Martinson, Variation of the elastic constants of sodium with temperature and pressure, Phys. Rev., 178(1969), no. 3, 902.

[37] M.W. Rarquardt, J.Trivisonno, Low temperature elastic constants of potassium, J. Phys. and Chem. Solids, 26(1965), no. 2, 273.

[38] D.R.Lide, Handbook of chemistry and physics, Boca Raton Fl, CRC Press, 2000.

[39] D.K.C.MacDonald, Self diffusion in the alkali metals, J. Chem. Phys., 21(1953), 177.

[40] W.Adlhart, G.Fritsch, E.Lüscher, Equilibrium defect properties of sodium in the high temperature range, J. Phys. and Chem. Solids, 36(1975), no. 12, 1405.

[41] J.N.Mundy, T.E.Miller, R.J.Porte, Self-diffusion in potassium, Phys. Rev. B, 3(1971), no. 8, 2445 .

[42] M.Doyama, J.S.Koehler, The relation between the formation energy of a vacancy and the nearest neighbor interactions in pure metals and liquid metals, Acta Metall, 24(1976), no. 9, 871-879.

[43] E.Hashimoto, E.A.Smirnov, T.Kino, Temperature dependence of the Doppler-broadened lineshape of positron annihilation in $\alpha$-Ti, J. Phys. F: Met. Phys., 14(1984), no. 10, L215.

[44] V.O.Shestopal, Specific heat and vacancy formation in titanium at high temperatures, Sov. Phys. Solid State, 7(1966), 2798-2800.

[45] G.M.Hood, R.J.Schultz, N.Matsuura, A positron annihilation spectroscopy study of Fe-free $\alpha$-Zr: Thermal equilibrium and irradiation effects, J. Nucl. Mater, 226(1995), no. 1\&2, 260-262.

[46] O. Le Bacq, F.Willaime, A.Pasturel, Unrelaxed vacancy formation energies in group-IV elements calculated by the full-potential linear muffin-tin orbital method: Invariance with crystal structure, Phys. Rev. B, 59(1999), no. 13, 8508-8515.

[47] G.M.Hood, R.J.Schultz, Temperature dependence of positron annihilation in $\alpha$-Hf, Materials Science Forum, vol. 175-178, Beijing (China), 1995, 375-378.

[48] I.K.Mackenzie, J.Fabian, Evidence from positron annihilation of anomalously low vacancy density in some metals with low melting points ,Can. J. Phys., 58(1980), no. 11, 1635-1639.

[49] E.A.Brandes, G.B.Brook, Smithells metal reference book, Oxford, Butterworths, 1992, $15-16$

[50] H.Ogi, S.Kai, H.Ledbetter, R.Tarumi, M.Hirao, K.Takashima, Titanium high-temperature elastic constants through the hcp-bcc phase transformation, Acta Materialia, 52(2004), 2075-2080.

[51] J.F.Smith, J.A.Gjevre, Elastic constants of yttrium single crystals in the temperature range 4.2-400K, J. Appl. Phys., 31(1960), 645-647.

[52] E.Fisher, C.Renken, Adiabatic elastic moduli of single crystal alpha zirconium, J. Nucl. Mater., 4(1961), 311-316.

[53] R.W.Ferris, M.L.Shepard, J.F.Smith, Elastic constants of thallium single crystals in the temperature range 4.2-300K, J. Appl. Phys., 34(1963), 768-770. 
[54] W.R.Tyson, W.A.Miller, Surface free energies of solid metals: Estimation from liquid surface tension measurements, Surface Science, 62(1977), no. 1, 267.

[55] V.Y.Gankin, Y.V.Gankin, General Chemistry Textbook/Chapter 11. Physical and chemical properties of substances/Theory of Metallic Bonding, Institute of the Theoretical Chemistry (http://itchem.com/theory_of_metallic_bonding).

\title{
Универсальный потенциал взаимодействия метода внедренного атома для чистых металлов
}

\section{В.Е. Зализняк \\ О.А. Золотов}

\begin{abstract}
Предлагается новый подход $к$ построению потенииала взаимодействия для металлов на основе метода внедренного атома. Из основных принципов квантовой механики задаётся аппроксимация распределения электронной плотности атомов, из которой следует не только парный потенииал взаимодействия, но и частично конкретный вид функиии внедрённой энергии. Для описания свойств конкретного металла требуется подобрать два параметра распределения электронной плотности и дополнительные параметры функции внедренной энергии. Подбор этих параметров осуществляется для равновесной решетки с использованием экспериментальных значений параметров решетки, энергии связи, энергии образования вакансии, упругих постоянных и поверхностной энергии. Приводятся потенииалы взаимодействия для 27 металлов с различными кристаллическими структурами. Общий вид потенциала имеет простую аналитическую форму и может использоваться для моделирования больших атомных систем в рамках метода молекулярной динамики.
\end{abstract}

Ключевые слова: потенииал межатомного взаимодействия, метод внедренного атома. 